Discussion Papers

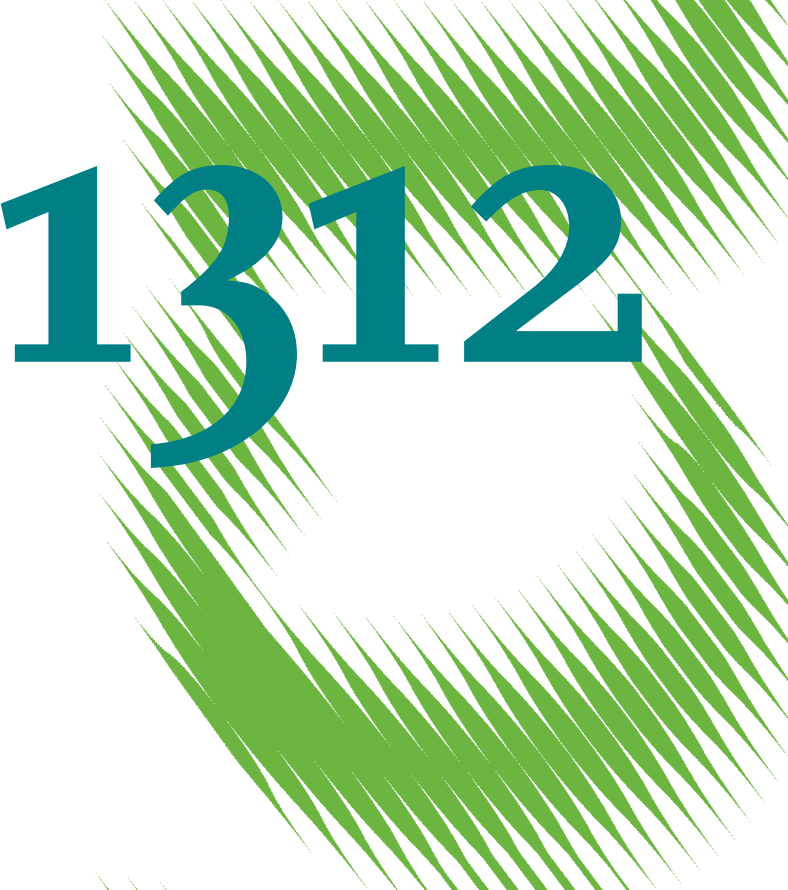

Power System Transformation towards Renewables: An Evaluation of Regulatory Approaches for Network Expansion 
Opinions expressed in this paper are those of the author(s) and do not necessarily reflect views of the institute.

IMPRESSUM

(C) DIW Berlin, 2013

DIW Berlin

German Institute for Economic Research

Mohrenstr. 58

10117 Berlin

Tel. $+49(30) 89789-0$

Fax +49 (30) $89789-200$

http://www.diw.de

ISSN print edition $1433-0210$

ISSN electronic edition 1619-4535

Papers can be downloaded free of charge from the DIW Berlin website:

http://www.diw.de/discussionpapers

Discussion Papers of DIW Berlin are indexed in RePEc and SSRN:

http://ideas.repec.org/s/diw/diwwpp.html

http://www.ssrn.com/link/DIW-Berlin-German-Inst-Econ-Res.html 


\title{
Power System Transformation towards Renewables: An Evaluation of Regulatory Approaches for Network Expansion
}

\author{
Jonas Egerer ${ }^{1}$, Juan Rosellón ${ }^{2}$, Wolf-Peter Schill ${ }^{3}$
}

July 2013

\begin{abstract}
We analyze various regulatory regimes for electricity transmission investment in the context of a transformation of the power system towards renewable energy. We study distinctive developments of the generation mix with different implications on network congestion, assuming that a shift from conventional power plants towards renewables may go along with exogenous shocks on transmission requirements, which may be either of temporary or permanent nature. We specifically analyze the relative performance of a combined merchant-regulatory price-cap mechanism, a cost-based rule, and a non-regulated approach in dynamic generation settings. Through application in a stylized two-node network, we find that incentive regulation may perform satisfactorily only when appropriate weights are used. While quasi-ideal weights generally restore the beneficial properties that incentive regulatory mechanisms are well-known for in static settings, pure Laspeyres weights may either lead to overinvestment (stranded investments) or delayed investments as compared to the welfare optimum benchmark. Stranded investments could then be avoided through proper handling of weights. Model results indicate that using average LaspeyresPaasche weights appears to be an appropriate strategy in the context of permanently or temporarily increasing network congestion. Our analysis motivates further research aimed to characterize optimal regulation for transmission expansion in the context of renewable integration.
\end{abstract}

JEL codes: Q40; Q42; L51

Keywords: Electricity transmission; incentive regulation; renewable integration; Laspeyres/Paasche weights; ideal weights.

\footnotetext{
${ }^{1}$ Technische Universität Berlin, Workgroup for Infrastructure Policy (WIP), Straße des 17. Juni 135, 10623 Berlin. Phone +49 30314 23649, je@wip.tu-berlin.de; and DIW Berlin, Department of Energy, Transportation, Environment, Mohrenstraße 58, 10117 Berlin. Phone +49 $3089789-674$, Fax+49 30897 89-113, jegerer@diw.de.

${ }^{2}$ CIDE, Department of Economics, Carretera México-Toluca 3655 Col. Lomas de Santa Fe 01210 México, D.F. juan.rosellon@cide.edu; and DIW Berlin, Department of Energy, Transportation, Environment, Mohrenstraße 58, 10117 Berlin. Phone +49 30897 89-497, Fax +49 30897 89-113, jrosellon@diw.de. Juan Rosellón acknowledges support from a Marie Curie International Incoming Fellowship within the 7th European Community Framework Programme, as well as from Conacyt.

${ }^{3}$ DIW Berlin, Department of Energy, Transportation, Environment, Mohrenstraße 58, 10117 Berlin. Phone +49 $3089789-$ 675, Fax+49 30897 89-113, wschill@diw.de.
} 


\section{Introduction}

The transformation towards a low carbon economy is one of the most ambitious projects of the European Union (EU) in the first half of the $21^{\text {st }}$ century. To promote this pathway, the EU formulates binding reduction targets until 2020 with the "20-20-20" goals. ${ }^{4}$ On a long-term perspective, until 2050, the implementation of discussed emission reduction targets of $80 \%$ (or more) is less concretely defined. Naturally, the predominant sectors for potential emission reductions are found in the energy system with electricity being of special importance. Fossil fuels are increasingly replaced by renewable generation technologies in the electricity sector. That the electricity system will have to integrate increasing shares of renewables is broadly accepted as most European states experience investments in new generation capacity of wind, solar, biomass and hydro plants. However, the response of the conventional generation park to the renewable integration process, both of existing capacity as well as of new investments, is less clear. In Europe, lignite, coal and natural gas (possibly with carbon capture and storage) or in some countries nuclear might build a bridge to the large-scale integration of non-conventional renewable technologies.

Regarding infrastructure, the transformation towards a low carbon economy requires new transmission capacity different to the historically existing one. However, network planning becomes increasingly complex under integration of renewable electricity. The role of network regulation in a dynamic renewable-integration process then arises as a challenging task. The owning transmission system operators (TSOs) carry out operation within the system while investments and decommissioning in renewable and conventional generation capacities, respectively, is taking place. Under a more centralized system with planning, the regulator should oversee that the transmission company (Transco) carries out the proposed planning. Under a more decentralized market structure, the regulator should provide investment incentives through regulatory mechanisms, such as cost-plus or incentive regulation. In any case, the regulator will require market information to carry out her functions under uncertainty in the development of generation and demand in the system. Typical regulatory challenges then include the implied impacts on network development, as well as the potential overinvestment by network operator during the renewable integration process, particularly in bridging technologies.

In this paper, we address the rationale for transmission investment under a renewable integration process. We isolate some basic characteristics and drivers for transmission investment in an energy

\footnotetext{
${ }^{4}$ The 20-20-20 goals for 2020 refer to: a reduction in EU greenhouse gas emissions of at least 20\% below 1990 levels; $20 \%$ of EU energy consumption to come from renewable resources, and a $20 \%$ reduction in primary energy use compared with projected levels, to be achieved by improving energy efficiency.
} 
transformation process characterized by network capacity expansion under the gradual substitution of conventional power (e.g., coal) with renewable energy sources (e.g., wind). We particularly compare the relative performance of a combined merchant-regulatory price-cap mechanism, using different weights, with cost-based regulation as well as with non-regulated approach in a dynamic system which assumes the transformation towards a power generation system with high renewable penetration.

The plan of the paper is as follows. In section 2 we carry out a literature review on regulation of transmission investment under market and renewable integration. In section 3 we present a transmission investment model that deals with the case of a changing market-setting under an intertemporally changing renewable-integration process. In section 4 , we provide fundamental stylized examples helpful to understand possible drivers of network congestion changes in the context of a transformation towards renewable power. For a simple two-node network, three distinctive developments of the generation mix with different implications on network congestion are presented. In section 5, we present the results of the relative performance of a combined merchant-regulatory price-cap mechanism, a cost-based rule, and a non-regulated approach under the dynamic generation settings. Section 6 concludes with a discussion on avenues for further research on the appropriate definition of weights for incentive regulation under renewable integration, as well of alternative objectives for transmission expansion for a low carbon electricity system. ${ }^{5}$

\section{Literature Review}

This paper analyzes the role of electricity transmission on the integration of renewable energy sources (RES). This presupposes possibility of the regulator of focusing on incentivizing investment from an independent Transco through adequate price regulation (see Vogelsang, 2001). This approach has gained importance, both in theory and practice, due to liberalization processes in various electricity systems that prioritize vertical separation, mainly between generation and transmission activities. Such unbundling measure has been shown to promote investment. Pollitt et al. (2007) review the econometric evidence and the international experience on generation and transmission unbundling (New Zealand, Australia, Chile, Argentina, Nordic Countries, and the USA) and conclude that, as opposed to other market architectures, unbundling of electricity generation and transmission - together with well-regulated independent transmission system operators (ITSOs) - can deliver highly competitive energy markets, and facilitate timely transmission investments. Newbery (2005) finds similar conclusions for the UK electricity market. Using OECD measures of product market reform, Alesina et al. (2005) also find that electricity investment increases as vertical integration decreases.

The role of transmission investment as a leading factor in the transformation of the whole electricity market via appropriate price signals from liberalization and regulatory reform processes is also

\footnotetext{
${ }^{5}$ Carbon pricing is of course a fundamental related issue on environmental regulation. High carbon prices would probably lessen the need for too many regulatory changes, as carbon prices directly enter marginal costs. If, in the contrary, carbon prices remain quite low the regulator might need to design more creative regulatory menus.
} 
recognized in most studies. Brunekreeft et al. (2005) and Rubio and Pérez-Arriaga (2000) point out the importance of a nodal-pricing system (and complementary capacity charges) to signaling the efficient location of generation investment. That is, establishing appropriate measures for incentivizing an efficient development of transmission networks - especially, through a developed nodal pricing system - is crucial not only for the development of the grid but also for other electricity sectors, such as generation, marketing, distribution and, even, system operation itself. Likewise, transmission planning in centralized systems, as well as incentivized transmission expansion in decentralized market architectures, have relevant impacts over consumer surplus and generator surplus (see Sauma and Oren, 2007, and Rosellón and Weigt, 2011).

A regulator has several alternatives to regulate the transmission price of a Transco in liberalized market environments. Cost-of-service (or cost-plus) regulation has been traditionally used in the practice of electricity utilities, mainly within the USA. It implies setting prices to equalize average cost, and usually goes along a restriction on the rate of return on capital. It has a basic advantage in that it provides certainty and long-run commitment by the regulator: two crucial elements for long-run investments of utilities. However incentives for cost minimization are almost nonexistent since the complete restitution of costs does not promote monetary expenditures for the improvement of efficiency. The other extreme of regulation, price-cap regulation, usually provides more incentives for cost minimization but at the cost of less certainty for the investing firm. This explains that price-cap schemes are usually combined in practice with cost-plus regulation.

Regarding regulation to promote electricity transmission investment of a transmission independent company (Transco), there are several alternatives. Two are especially interesting for the approach that we use in this paper: one based on financial transmission rights (FTRs, merchant approach), and another based on the incentive price-cap regulation. The merchant approach is based on FTR auctions within a bid-based security-constrained economic dispatch with nodal pricing of an independent system operator (ISO). The ISO runs a power-flow model that provides nodal prices derived from shadow prices of the model's constraints. FTRs are subsequently calculated as hedges from nodal price differences. The ISO retains some capacity or FTRs in order to deal with externalities caused by loop-flows, so that the agent expanding a transmission link implicitly pays back for the possible loss of property rights of other agents (Bushnell and Stoft, 1997, Kristiansen and Rosellón, 2006). FTR auctions have been implemented mainly in Northeast USA (NYISO, PJM ISO, and New England ISO).

The incentive approach relies on a price-cap on the two-part tariff of an independent Transco (Vogelsang, 2001). ${ }^{6}$ Incentives for efficient investment result in expansion of the transmission grid through the over-time rebalancing of the fixed and variable charges of the two-part tariff. Convergence

\footnotetext{
${ }^{6}$ A Transco needs to be regulated since it is a natural monopoly. Vogelsang (2001) concentrates on incentive regulation natural-monopolistic activities of the Transco, independently from power generation.
} 
to steady state Ramsey-price equilibrium relies on the type of weights used. Transmitted volumes for each type of service are used as weights for the corresponding various prices so that the Transco's profits grow as capacity utilization and network expansion increase. In equilibrium, the rebalancing of fixed and variable charges depends on the ratio between the output weight and the number of consumers. There are two basic ways to regulate price structure: one with fixed weights --tariff-basket regulation-- and another with variable weights --average revenue regulation--. Under the former regime, a maximum limit is established over an index $I(p)=\sum_{i=1}^{n} w_{i} p_{i}$ where $p_{i}$ are the different prices and $w_{i}$ are the fixed weights. Weights might be output (or throughput) quantities of the previous period (chained Laspeyres), quantities of the current period (Paasche), intertemporally fixed quantities (fixed Laspeyres), or projected quantities that correspond to the steady state equilibrium (ideal Laffont-Tirole weights, as in Laffont and Tirole, 1996). ${ }^{7}$ Variable weights are usually associated with averagerevenue regulation which sets a cap on incomes per unit but that does not set fixed weights that limit the relative variation of prices. Compared to tariff-basket regulation, this confers the firm greater flexibility in tariff rebalancing but lack of convergence to the welfare maximizing equilibrium. The literature has proved that, under non-stochastic (or stable) conditions of costs and demand and myopic profit maximization (that is, when the firm does not take into account future periods in its current profit maximizing behavior), the use of the chained Laspeyres index makes the prices of the regulated firm intertemporally converge to Ramsey-Boiteaux pricing (Vogelsang, 2001, Vogelsang, 1989, Bertoletti and Poletti, 1997, Loeb and Magat 1979, and Sibley, 1989). The chained-Laspeyres structure simultaneously reconciles two opposing objectives: the maximization of social welfare and the individual rationality of the firm (i.e., non-negative profits). Social surplus is redistributed to the monopoly in such a way that long-run fixed costs are recovered but, simultaneously, consumer surplus is maximized over time. ${ }^{8}$

Tanaka (2007) also proposes various incentive mechanisms: a Laspeyres-type price-cap on nodal prices, a two-part tariff cap also based on Laspeyres weights, and an incremental surplus subsidy, where the regulator observes the actual cost but not the complete cost function. These mechanisms are shown to achieve optimal transmission capacity from the effects of capacity expansion on flows and welfare. However, both Tanaka (2007) and Vogelsang (2001) abstract from technical electricity transmission constraints (loop-flows), and assume well-behaved transmission capacity cost functions, heroic assumptions for loop-flowed meshed electricity networks.

A combination of the merchant and the incentive-regulation approaches was developed by Hogan, Rosellón and Vogelsang (Hogan et al. 2010, HRV). A crucial aspect here is the redefinition of the

\footnotetext{
${ }^{7}$ The steady state equilibrium is characterized by prices whose optimal distance from marginal cost is inversely proportional to the elasticity of demand. These are referred in the literature as the Ramsey-Boiteaux prices (see Armstrong et al. 1994, chapter 3).

${ }^{8}$ The social surplus is made up by consumer surplus, the producer surplus, and the government surplus (if present).
} 
transmission output in terms of incremental FTRs in order to apply the same regulatory logic of Vogelsang (2001) to real-world networks within a power-flow model. The HRV model deals with loop-flows in meshed networks, and achieves well behaved transmission cost functions (Rosellón et al. 2012). The Transco intertemporally maximizes profits subject to a cap on its two-part tariff, but the variable fee is now the price of the FTR output based on nodal prices. Although immerse in an intertemporal regulated profit-maximizing environment, the bi-level HRV model really assumes a static market setting in the sense of identical output behavior during each period. The Transco is actually a player enabled to alter the market result over time as it decides investments in transmission infrastructure (upper-level problem). Additional transmission lines change the constraints on the network (flow pattern and capacity), and therefore typically allow for an improved market dispatch with higher welfare (lower-level problem). The Transco is allowed to get a share of the welfare gains due to its two-part tariff structure. The fixed fee of the tariff inter-temporally rebalances (with respect to the variable fee) to make up for lost congestion rents, and convergence to steady-state equilibrium is achieved through the use of proper weights (typically, Laspeyres weights). The approach also applies to more general situations including more realistic electricity flows like DC load-flow with loop-flows. The HRV model has already been successfully tested in simplified grids of Western Europe, Northeast USA and South America (see Rosellón and Weigt, 2011, Rosellón et al. 2011, and Ruíz and Rosellón, 2012).

Allowing for regional (nodal) prices provides economic incentives for investments in the transmission network through congestion prices on every network link. With the HRV mechanism, the regulator promotes network developments that relief congestion with a system which provides the Transco with incentives to invest rewarding welfare beneficial investments through an increased regulated return in the two-part tariff. This mechanism works as long as the welfare changes in the system can be directly linked to transmission investment. In the current HRV research, however, the complex issue of interaction between generation, transmission and demand has not yet been considered.

Naturally, other incentive mechanisms for transmission investment exist in the literature. For instance, Léautier (2000) and Joskow and Tirole (2002) propose mechanisms based on a measure of welfare loss with respect to the Transco's performance. The regulator rewards the Transco when the capacity of the network is increased so that congestion rents are decreased. The regulator also might punish the Transco for taking advantage of a congested network by charging increasing fees, and accumulating higher congestion rents. ${ }^{9}$ Alternatively, Contreras et al. (2009) propose an incentive scheme for transmission expansion based on a cooperative-game model where the Shapley value is used to reward investors according to their value added to social welfare.

\footnotetext{
${ }^{9}$ Another variation is an "out-turn" based regulation. The out-turn is defined as the difference between the price for electricity actually paid to generators and the price that would have been paid absent congestion (Léautier, 2000). The Transco is made responsible for the full cost of out-turn, plus any transmission losses
} 
One common feature across all of the above incentive regulation mechanisms is that they rely on a market-integration economic rationale that is, on the efficient expansion of the transmission network to the nodes with cheapest generation technologies. This objective is also usual in legislation on tasks for regulation, for example in the planning of the development of the transmission grid in Germany (50Hertz et al. 2012). Market integration then integrates the transmission system to low variable cost generation plants (but possibly with high carbon emissions), reducing total dispatch costs.

Schill et al. (2011) study the performance of various regulatory mechanisms under transmission market integration and varying demand and wind generation. They specifically compare the HRV mechanism to a cost-based and a non-regulated approach with hourly time resolution in demand and fluctuating wind power. They show that HRV regulation leads to welfare outcomes far superior to the other modeled alternatives. The analysis by Schill et al. (2011) is carried out assuming intertemporal stability on the power generation mix. However, a system with increasing shares of generation from renewable energy sources (RES) will need to be combined at least temporally with conventional base-, mid-, and peak-load generation. Therefore, network extensions for combined integration of carbonintensive base-load and RES generation might face the risk of excessive stranded transmission investments in the medium term. ${ }^{10}$ We study in this paper this basic issue with a simple model presented in the following section.

\section{The Model}

We follow the approach of Schill et al. (2011). Table 4 in the Appendix lists all model sets and indices, parameters, and variables. We assume a market design with nodal pricing based on real power flows. A single Transco holds a natural monopoly on the transmission network. The Transco decides on network extension. Accordingly, we just assume that the Transco maximizes profit, which consists of congestion rents and - depending on the regulatory regime - a fixed income part. Whereas the Transco is not involved in electricity generation, an independent system operator (ISO) manages the actual dispatch in a welfare-maximizing way. The ISO collects nodal payments from loads and pays the generators. The difference between these payments is the congestion rent, which is assumed to be transferred to the Transco. We model three different regulatory cases in which we assume the Transco to be unregulated regarding network expansion (NoReg), cost-regulated (CostReg), or HRV-regulated. We compare these regulatory cases to a baseline case without any network expansion (NoExtension) and to a welfare-maximizing benchmark (WFMax), in which a social planner makes combined decisions on network expansion and dispatch. The problem formulation entails two decision levels (bilevel programming). In the regulatory cases, the Transco's profit maximization constitutes the upper-level optimization problem. In the welfare-maximizing benchmark, the upper-level program

\footnotetext{
${ }^{10}$ We assume perfect foresight regarding the changing generation mix. Van der Weijde and Hobbs (2012) study the economics of electricity transmission planning under uncertain economic, technological, and regulatory conditions.
} 
represents the social planner's maximization problem. On the lower level, we formulate the ISO's welfare-maximizing dispatch as a mixed complementarity problem (MCP). The combination of lower and upper level problems constitutes a mathematical program with equilibrium constraints (MPEC). ${ }^{11}$ We assume a standard linear demand function (1):

$$
p_{n, t, \tau}=a_{n, \tau}+m_{n, \tau} q_{n, t, \tau}
$$

where $p_{n, t, \tau}$ is the electricity price at node $n$ in regulatory period $t$ and hour $\tau^{12}$, whereas $q_{n, t, \tau}$ describes the corresponding electricity demand. Given (1), the lower level dispatch problem consists of equations (2)-(9). These represent an MCP formulation of the ISO's constrained welfare maximization problem, which is provided in the Appendix. We model real load flows between single nodes with the simplified DC load flow approach (Schweppe et al. 1988, Leuthold et al. 2012). Equations (2)-(9) must be satisfied in every single hour $\tau$.

$$
\begin{array}{ll}
a_{n, \tau}+m_{n, \tau} q_{n, t, \tau}-p_{n, t, \tau} \leq 0 & \perp q_{n, t, \tau} \geq 0 \\
-C_{s}+p_{n, t, \tau}-\lambda_{4, n, s, t, \tau} \leq 0 & \perp g_{n, s, t, \tau} \geq 0 \\
-\sum_{l \in L} \frac{I_{l, n}}{X_{l, t}} \lambda_{1, l, t, \tau}+\sum_{l \in L} \frac{I_{l, n}}{X_{l, t}} \lambda_{2, l, t, \tau}-\sum_{n n} p_{n n, t, \tau} B_{n n, n, t}-\lambda_{5, n, t, \tau} \text { slack }_{n}=0, \Delta_{n, t, \tau} & \text { free } \\
\sum_{n} \frac{I_{l, n}}{X_{l, t}} \Delta_{n, t, \tau}-P_{l, t} \leq 0 & \perp \lambda_{1, l, t, \tau} \geq 0 \\
-\sum_{n} \frac{I_{l, n}}{X_{l, t}} \Delta_{n, t, \tau}-P_{l, t} \leq 0 & \\
\sum_{s} g_{n, s, t, \tau}-\sum_{n n} B_{n, n n} \Delta_{n n, t, \tau}-q_{n, t, \tau}=0 & \perp \lambda_{2, l, t, \tau} \geq 0 \\
g_{n, s, t, \tau}-\bar{g}_{n, s, t} \leq 0 & \\
\text { slack } \Delta_{n, t, \tau}=0 & p_{n, t, \tau} \\
\text { free }
\end{array}
$$

Equations (2)-(4) represent the partial derivates with respect to $q_{n, t, \tau}, p_{n, t, \tau}$, and the voltage angle $\Delta_{n, t, \tau} . I_{l, n}$ is the incidence matrix of the network, which provides information on how the nodes are

\footnotetext{
${ }^{11}$ Hobbs et al. (2000) were among the first to apply an MPEC approach to power market modelling. See also Gabriel et al. (2013).

${ }^{12}$ In the numerical application in section 4, we do not make use of the hourly resolution of the model formulation. Instead, we rely on stylized average values.
} 
connected by transmission lines $l$. The parameter $X_{l, t}$ describes the reactance for each transmission line. $B_{n, n n}$ is the network susceptance between two nodes. Equations (5) and (6) demand that the power flows on each line do not exceed the respective line's capacity $P_{l, t}$. (7) ensures nodal energy balance: generation minus net outflow has to equal demand at all times. Equation (8) constrains generation of technology $s$ to the maximum available generation capacity at the respective node and the respective time period. Finally, (9) establishes a point of reference for the voltage angles by exogenously setting the parameter slack ${ }_{n}$ to 1 for one node in the network. For all other nodes, slack $_{n}$ equals 0.

Whereas the lower-level problem (2)-(9) has to be solved for every single hour $\tau$, the upper-level problem needs to be inter-temporally optimized over all regulatory periods $t$. For the three regulatory regimes, the upper level problem is represented by (10):

$$
\max \Pi=\sum_{t \in T}\left(\left(\sum_{\tau \in \mathrm{T}} \sum_{n \in N}\left(p_{n, t, \tau} q_{n, t, \tau}-\sum_{s \in S} p_{n, t, \tau} g_{s, n, t, \tau}\right)+\text { fixpart }_{t}-\sum_{l \in L} \sum_{t t<t} e c_{l} \operatorname{ext}_{l, t t}\right) \frac{1}{\left(1+\delta^{p}\right)^{t-1}}\right)
$$

The Transco's decision variable is capacity extension of transmission lines ext $t_{l, t}$, which incurs extension costs $e c_{l}$ (annuities). In the NoReg case, transmission investments have to be fully recovered by congestion rents, i.e. fixpart $_{t}=0$. Accordingly, the Transco will only extend such lines that increase congestion rents. Both future revenues and future costs are discounted with a private discount rate $\delta^{p}$. In the CostReg case, we assume that the Transco not only receives congestion rents,

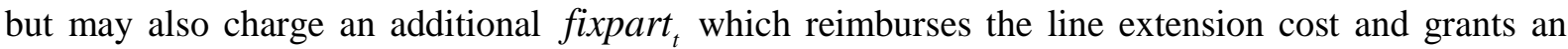
additional return on costs ("cost-plus" regulation). Equation (11) shows that the fixed part of a given period includes the costs (annuities) of all network investments made so far plus a return on costs $r$. With positive $r$, the Transco may find it optimal to expand all transmission lines infinitely. We thus include an additional constraint stating that equation (11) only holds as long as line extension does not exceed the optimal levels as determined by the welfare-maximizing benchmark. ${ }^{13}$ In the HRV case, the Transco may also charge a fixed tariff part, on which equation (12) sets a cap. It includes current and previous period quantity weights $q_{n, t, \tau+1}^{\text {weight }}, q_{n, t, \tau}^{\text {weight }}, g_{s, n, t, \tau+1}^{\text {weight }}$ and $g_{s, n, t, \tau}^{\text {weight }}$. In its general form, it also includes a retail price index $R P I$ and an efficiency factor $X$. We set both $R P I$ and $X$ to zero in the model application, as we assume real prices and neglect efficiency gains. Summing up, in both the CostReg and the $H R V$ cases, the Transco is able to recover network extension costs by the fixed tariff

\footnotetext{
${ }^{13}$ Note that this requires the regulator to have sufficient knowledge on which lines should be increased.
} 
part. In contrast, this is not true in the NoReg case, in which the Transco will only invest in transmission extension if it leads to increases in congestion rents that are larger than extension costs.

$$
\begin{gathered}
\text { fixpart }_{t+1}^{\text {CostReg }}=\sum_{l \in L} \sum_{t t<t+1} \text { ec }_{l} \text { ext }_{l, t t}(1+r)+\text { fixpart }_{t}^{\text {CostReg }} \\
\frac{\sum_{\mathrm{n} \in \mathrm{N}} \sum_{\tau \in \mathrm{T}}\left(p_{n, t+1, \tau} q_{n, t, t+1}^{\text {weight }}-\sum_{s \in S} p_{n, t+1, \tau} g_{s, n, t, \tau+1}^{\text {weight }}\right)+\text { fixpart }_{t+1}^{\text {HRV }}}{\sum_{\mathrm{n} \in \mathrm{N}} \sum_{\tau \in \mathrm{T}}\left(p_{n, t, \tau} q_{n, t, \tau}^{\text {weight }}-\sum_{s \in S} p_{n, t, \tau} g_{s, n, t, \tau}^{\text {weight }}\right)+\text { fixpart }_{t}^{\text {HRV }}} \leq 1+R P I-X
\end{gathered}
$$

Table 1 provides an overview of the different types of weights used in the analysis. Ideal weights are

\begin{tabular}{|c|c|c|c|c|}
\hline & Laspeyres & Paasche & $\begin{array}{c}\text { Average } \\
\text { Laspeyres-Paasche }\end{array}$ & (Quasi-) Ideal $^{14}$ \\
\hline$q_{n, t, t+1}^{\text {weight }}$ & $q_{n, t, \tau}$ & $q_{n, t, \tau+1}$ & $\frac{1}{2}\left(q_{n, t, t+1}+q_{n, t, \tau}\right)$ & $q_{n, t, \tau+1}^{*}$ \\
\hline$q_{n, t, \tau}^{\text {weight }}$ & $q_{n, t, \tau}$ & $q_{n, t, t+1}$ & $\frac{1}{2}\left(q_{n, t, \tau+1}+q_{n, t, \tau}\right)$ & $q_{n, t, \tau}^{*}$ \\
\hline$g_{s, n, t, \tau+1}^{\text {weight }}$ & $g_{s, n, t, \tau}$ & $g_{s, n, t, \tau+1}$ & $\frac{1}{2}\left(g_{s, n, t, \tau+1}+g_{s, n, t, \tau}\right)$ & $g_{s, n, t, \tau+1}^{*}$ \\
\hline$g_{s, n, t, \tau}^{\text {weight }}$ & $g_{s, n, t, \tau}$ & $g_{s, n, t, \tau+1}$ & $\frac{1}{2}\left(g_{s, n, t, \tau+1}+g_{s, n, t, \tau}\right)$ & $g_{s, n, t, \tau}^{*}$ \\
\hline
\end{tabular}
derived from welfare-optimal results (indicated by an asterisk).

Table 1: Overview of weights

In the baseline and in the welfare-maximizing benchmark case, the upper level problem does not represent a Transco's profit-maximization, but a social planner's maximization of social welfare. It is described by (13). The social planner uses a social discount rate $\delta^{s}$, which may be smaller than the private discount rate $\delta^{p}$ used by a Transco. ${ }^{15}$

\footnotetext{
${ }^{14}$ Following Laffont and Tirole (1996) would require using last-period quantities, not period-specific ones. However, in a dynamic generation setting with an exogenously changing generation mix, in which there may be no smooth convergence to a steady state, our quasi-ideal period-specific weights perform better.

${ }^{15}$ In the model application, we assume $\delta^{s}=0.04$ and $\delta^{p}=0.08$.
} 
$\max w f=\sum_{t \in T}\left(\left(\sum_{\tau \in \mathrm{T}} \sum_{n \in N}\left(a_{n, \tau} q_{n, t, \tau}+\frac{1}{2} m_{n, \tau} q_{n, t, \tau}{ }^{2}-\sum_{s \in S} c_{s} g_{s, n, t, \tau}\right)-\sum_{l \in L} \sum_{t t<t} e c_{l} \operatorname{ext} t_{l, t t}\right) \frac{1}{\left(1+\delta^{s}\right)^{t-1}}\right)$

In all regulatory cases, network extension leads to inter-period constraints on line capacity (14), line reactance (15) and network susceptance (16).

$$
\begin{gathered}
P_{l, t+1}=P_{l, t}+e x t_{l, t} \\
X_{l, t}=\frac{P_{l}^{0}}{P_{l, t+1}} X_{l}^{0} \\
B_{n n, n, t+1}=\sum_{l} \frac{I_{l, n} I_{l, n n}}{X_{l, t+1}}
\end{gathered}
$$

The problem is implemented in the General Algebraic Modeling System and solved using the commercial solver NLPEC. As the feasible region of the MPEC problem is non-convex, a large number of different starting points are used in order to find good local optima. ${ }^{16}$ First, the welfareoptimal benchmark and all regulatory cases are solved using the case without expansion as a starting point. Second, all cases are repeatedly solved with the solution of WFMax serving as a starting point. Afterwards, all cases are repeatedly solved in varying order, using the (feasible) solution of one case as a starting point for the next case. We find that local optima converge to some characteristic values during this solution procedure. After several iterations, solutions do not improve any more. The best available solutions are then considered as good approximations of global optima.

\section{Test cases}

The locations of renewable power generation usually differ from the ones of conventional power plants. For example, lignite plants are always located nearby lignite mines in order to minimize transportation costs. Likewise, hard coal plants are usually built in such locations where the coal can easily be shipped. In contrast, wind power plants are usually constructed at places where their natural potential is greatest, for example at coast lines or even offshore. Solar power is often installed near the load, for example on roof tops. Thus both (centralized) wind power and (decentralized) solar power may lead to very different transmission requirements compared to conventional power plants. Accordingly, an energy system transformation towards renewable power supply may either increase or decrease congestion in existing transmission systems.

Exactly how network congestion changes in the context of such an energy transformation depends very much on the existing transmission system, the choice of renewable technologies (for example,

\footnotetext{
${ }^{16}$ In addition, we make use of numerical scaling in order to improve the solution process.
} 
wind or solar power), and the timeframe considered. We thus analyze four stylized cases of changing generation capacities in a simple two-node network (n1, n2) over a timeframe of 20 years. ${ }^{17}$ Both nodes are connected by a capacity-constrained transmission line with a bi-directional capacity of $50 \mathrm{MW}$ in the initial period. Figure 1 shows the network setting in the initial period.

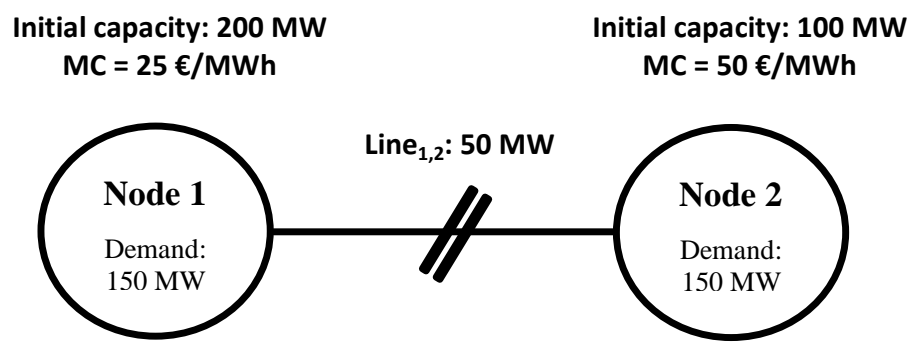

Figure 1: The network setting in the initial period

Demand at both nodes is characterized by a linear demand curve with a reference demand of $150 \mathrm{MW}$ at a reference price of $30 € / \mathrm{MWh}$. The price elasticity of demand is -0.25 at the reference point. There are two conventional generation technologies (base, peak) with marginal costs of $25 € / \mathrm{MWh}$ and $50 € / \mathrm{MWh}$, respectively. The cheap conventional technology is assumed to be located at node 1 , the expensive technology at node 2 . Renewable power is dispatched without marginal costs, which is true for both wind and solar power. For reasons of simplicity, we abstract in our model of section 3 from fluctuations in demand and in renewable generation. The four stylized cases generation capacity changes are (see Figure 2):

1) The static case: There are no changes in generation technologies over time.

2) Temporarily increased congestion: Increasing generation capacities of renewable sources at node 1. This could be interpreted as wind power replacing hard coal plants in coastal areas. There is an overlap of renewables phasing in and conventional generators phasing out, such that congestion is temporarily increased.

3) Permanently increased congestion: Growing renewable capacities at node 1 over-compensate the phase-out of conventional power plants at this node, giving rise to temporarily increased congestion.

4) Permanently decreased congestion: Renewable power generation increases equally at both nodes, for example wind power at node 1 and solar power at node 2, such that conventional generation is completely phased out. Consequently, transmission congestion vanishes.

\footnotetext{
${ }^{17}$ There is only one representative hour $\tau$.
} 


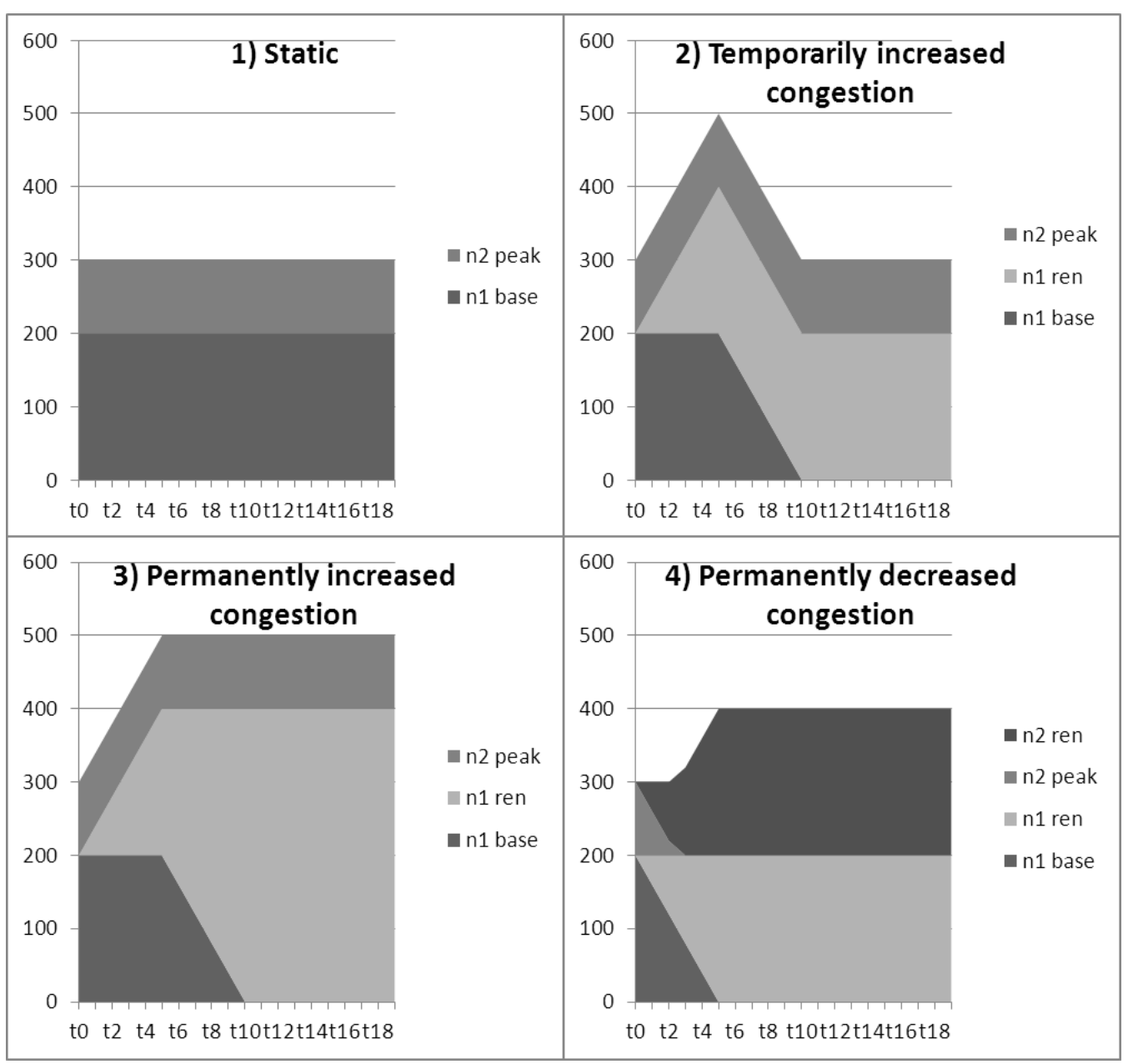

Figure 2: Exogenous development of generation capacities in different cases

Figure 3 provides more intuition on the transmission congestion implications of the assumed intertemporal behaviors of the generation mix. It shows how network congestion develops in all cases due to the exogenous changes in generation capacity discussed above, assuming that no network expansion takes place in any period. Note the temporally increased congestion between t 1 and t9 in case 2) due to the delayed phase out of conventional generation in node 1, compared to the two jumps in congestion rent in period t1 and t6 in case 3), which is the result of conventional capacity phasing out at node 1 and zero cost renewables setting the price at this node. In case 4), network congestion vanishes completely from $\mathrm{t} 3$ on. 


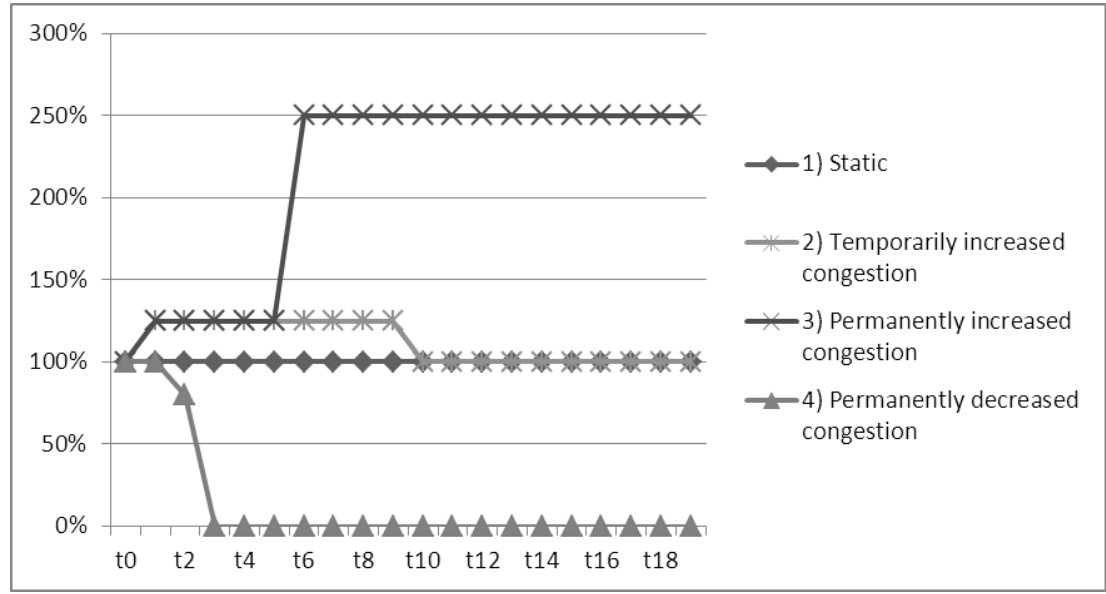

Figure 3: Development of the congestion rent (without network expansion)

In section 5, we analyze the effects of the three regulatory regimes on transmission expansion and welfare in all of the above cases. We compare them to the baseline without expansion and the welfaremaximizing optimum. We first do so using Laspeyres weights in the $H R V$ model. Afterwards, we try out other possibilities such as Paasche weights, average Laspeyres-Paasche weights and ideal weights. The purpose is to analyze the implications of each type of weights on convergence to optimal investment and welfare, so as to characterize optimal incentive regulation for transmission expansion in a transforming power system.

\section{Results}

\subsection{Laspeyres weights}

Figure 4 shows network expansion results for the two-node cases. In the static case - in which generation capacities do not change over time - line expansion under $H R V$ regulation converges to the welfare-optimal level over time. In contrast, both the cost-regulatory case and the scenario without regulation do not lead to network expansion. These findings confirm the results of previous numerical simulations (Rosellón and Weigt, 2011, Rosellón et al. 2011, Schill et al. 2011, and Ruiz and Rosellón, 2012). 


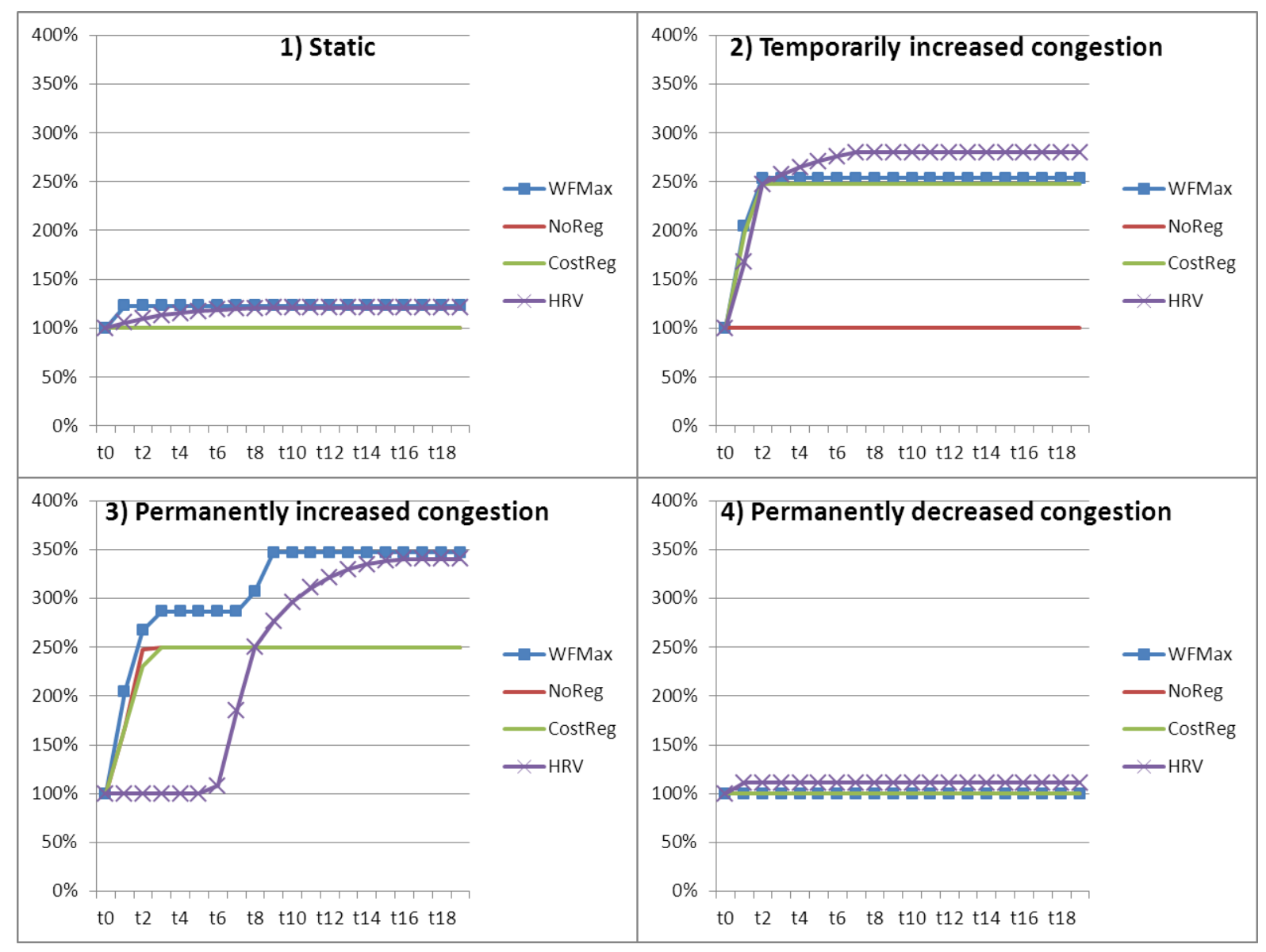

Figure 4: Line extension results (relative to initial line capacity, Laspeyres weights)

In the cases with exogenously changing generation capacities, however, these results do not necessarily hold any longer. In case 2), which assumes temporarily increased network congestion due to growing renewable capacities, $H R V$ leads to over-investments as compared to the welfare optimal benchmark. When rebalancing the fixed and variable tariff parts according to the regulatory cap, the Transco is rewarded for stranded investments. The main reason for this finding is that the chosen Laspeyres weights (previous period quantities) are not optimal, as they do not reflect exogenous decreases in congestion rents in future periods and they incorporate congestion-rents gains arising both from the transmission expansion process as well as from the change in the generation mix. In contrast, the cost-regulatory approach leads to a desirable network expansion.

In case 3) with permanently increased congestion, $H R V$-triggered network expansion approaches optimal levels in the final periods. However, the Transco finds it optimal not to invest before the seventh period, as it benefits much of increased congestion rents in the first periods, which are rebalanced against growing fixed parts later on. In contrast, both the cost regulatory case and NoReg lead to substantial line capacity extension in early years; however, these do not provide incentives to the Transco to expand capacity to optimal levels in later periods. 
In case 4), we do not find any network investments in the welfare-optimal case, as congestion decreases exogenously and vanishes completely after period 3. CostReg and NoReg also do not lead to any network investment. Yet under $H R V$ regulation, the Transco finds some investments to be profitable, as the regulatory cap rewards it for removing congestion in the first periods.

As a consequence of the line investments shown in Figure 4, we find (nominal) congestion rents to develop as shown in Figure 5. Whereas $H R V$ regulation largely removes congestion rents over time in the static case, it leads to overly reduced congestion in case 2, in which the exogenous congestion shock is only of temporary nature. A related observation can be made in case 4 . Yet in case 3, we find that the Transco's delay of investments enables it to benefit from relatively very high congestion rents around the ninth period, which it is then able to rebalance with the fixed part in the following periods. As shown in Figure 6, the Transco is even willing to choose a negative fixed part in the first periods in order to "make room" for even higher fixed parts in future. ${ }^{18}$

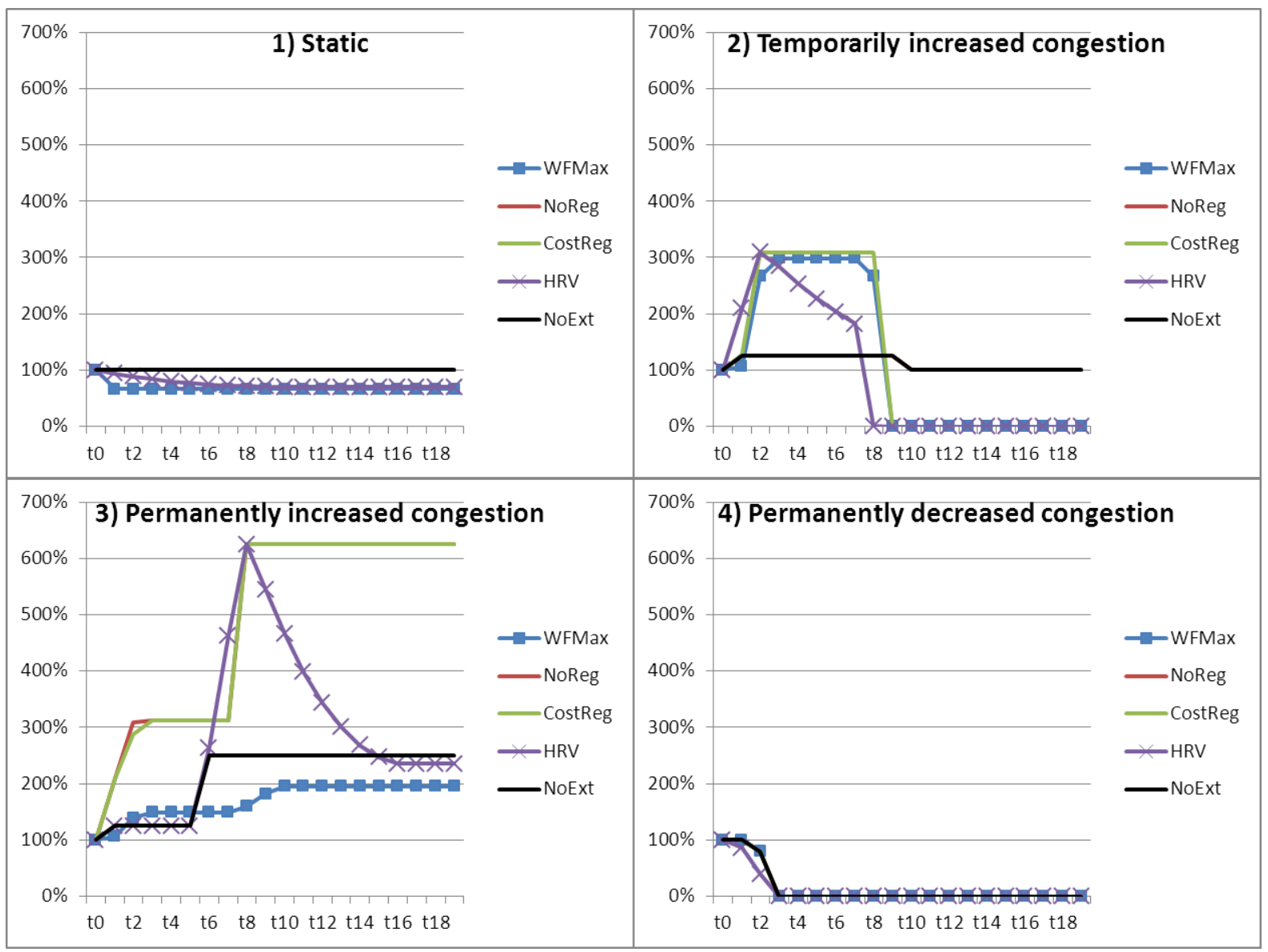

Figure 5: Congestion rents (nominal values)

\footnotetext{
${ }^{18}$ Absolute numbers of the ordinate (in Euro) are actually irrelevant due to the stylized nature of the 2-node example.
} 


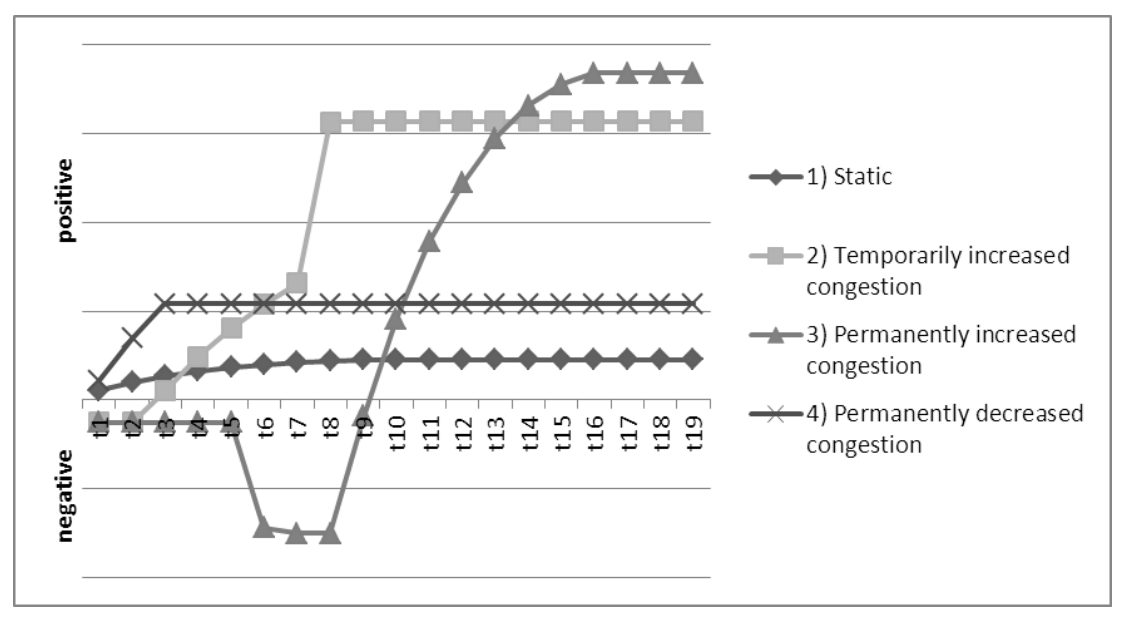

Figure 6: Development of the fixed part in case of HRV regulation

\subsection{Other Types of Weights}

The results presented so far show that some of the properties of the combined merchant-regulatory incentive regulation as established in the literature may not hold any longer in the context of exogenous changes of generation capacities when Laspeyres weights are used. In the next subsections, we study the effects of using other type of weights in the $H R V$ regulatory-cap formula.

\subsubsection{Paasche weights}

Paasche weights use same-period quantities as weights in the regulatory constraint. They have been theoretically shown in the literature to lead to overinvestment under incentive regulation (Vogelsang, 2001). We in fact confirm this in our simulations. Figure 7 depicts network expansion results for the modeled cases. In all cases, line expansion under $H R V$ regulation notably exceeds the welfare-optimal level over time. Compared to Laspeyres weights, Paasche weights do not reflect exogenous decreases in congestion rents in future periods even at a larger scale. Another difference to Laspeyres weights refers to the fact that total network extension is carried out in the first period in cases 1 and 4 . This contrasts to gradual line extension in the Laspeyres case. 


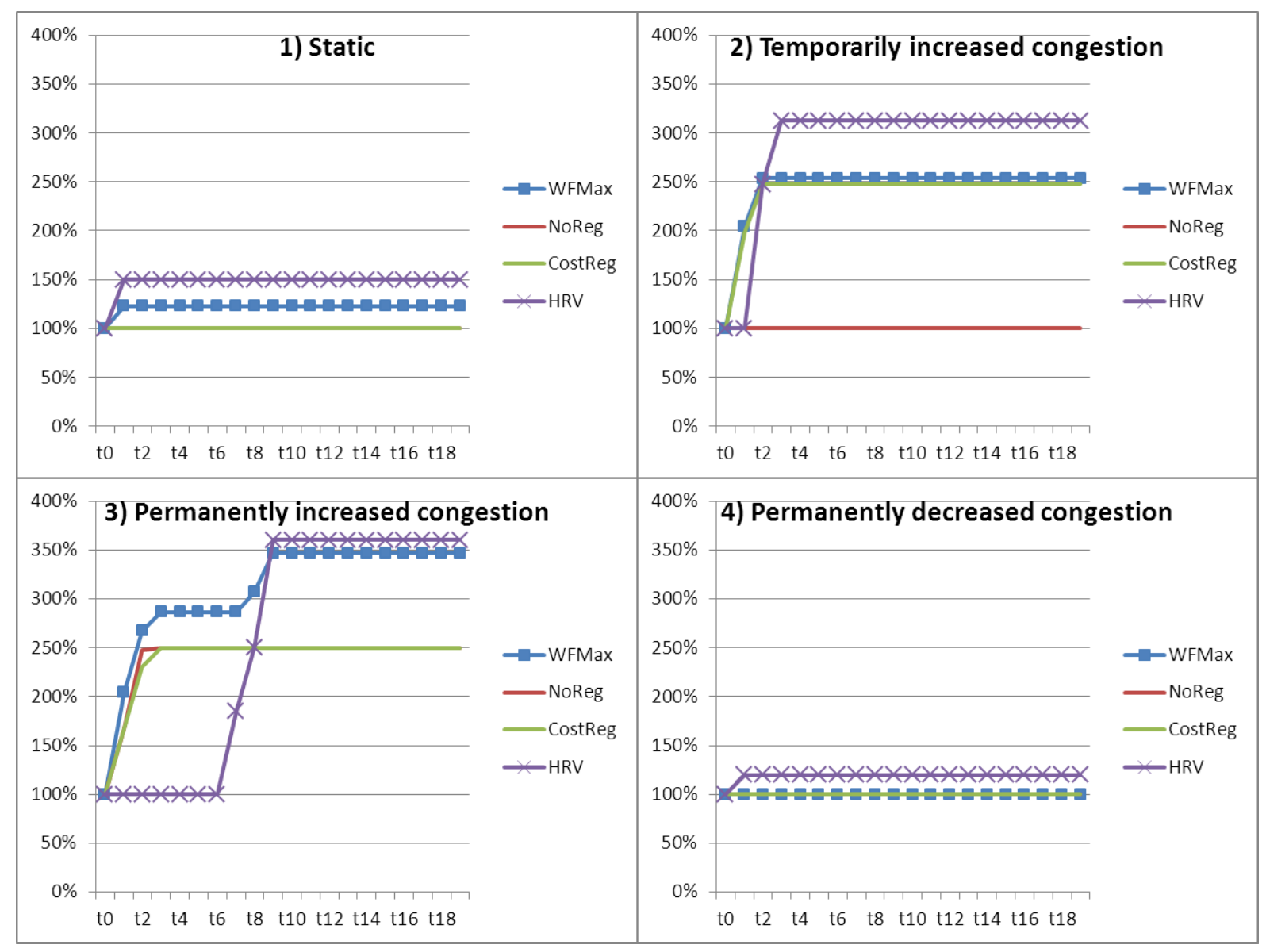

Figure 7: Line extension results (relative to initial line capacity, Paasche weights)

\subsubsection{Ideal weights}

Ideal weights are quantities corresponding to the steady-state equilibrium and have been analytically shown to grant convergence of incentive mechanisms to such equilibrium in just one period (Laffont and Tirole, 1996). In the following simulation, we use "quasi"-ideal weights defined as the periodspecific quantities of the welfare-optimal runs for each case. ${ }^{19}$ Figure 8 confirms the theory of incentive regulation under renewable integration. The $H R V$ incentive mechanisms nicely converge early to the welfare-optimal benchmark investment in all cases. The ideal weights then achieve to isolate purely the incentive transmission effects to invest from the generation-mix change effects. Meanwhile, for cost-plus regulation we observe the same behavior as in the previous cases.

\footnotetext{
${ }^{19}$ Ideal weights serve as benchmarks. In practice, they may not be available to the regulator as they cannot be observed from market outcomes.
} 


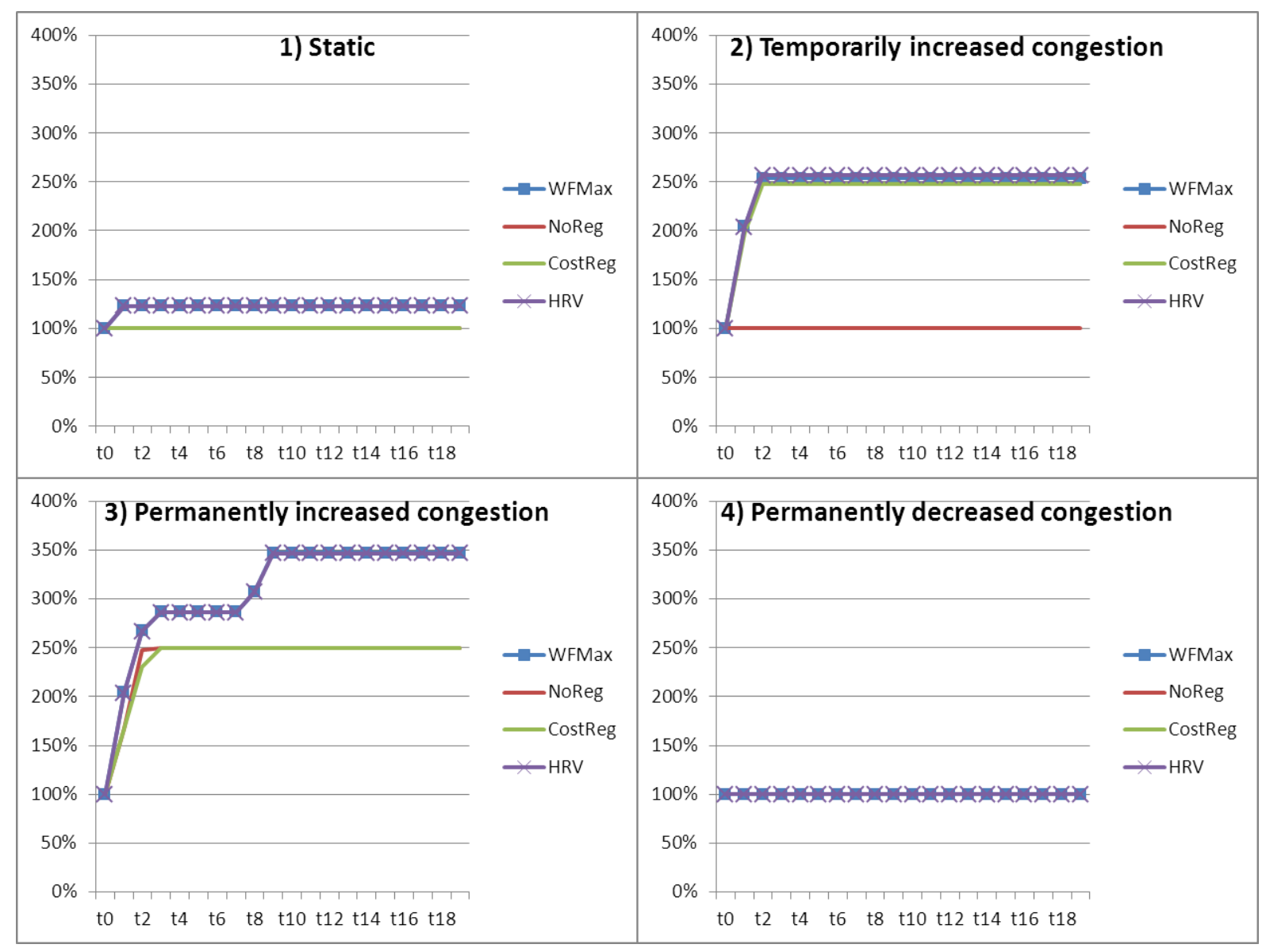

Figure 8: Line extension results (relative to initial line capacity, ideal weights)

\subsubsection{Average Laspeyres-Paasche weights}

A simple average of Laspeyres and Paasche weights has been used in the literature as a linear approximation of idealized weights (Vogelsang, 2001). They are exact only for linear demand curves and may in theory lead to strategic behaviour (cycles) if demands are nonlinear, but this has not practical significance (Vogelsang, 1988). In our simulations, we confirm that, under $H R V$ regulation, this type of weight actually leads to faster network expansion and less overinvestment in cases 2 and 3 (see Figure 9). Noticeably, in the static case total network extension is carried out in the first period, as was also observed in the case of Paasche weights. This once again contrasts to the Laspeyres case, in which lines are extended gradually. 


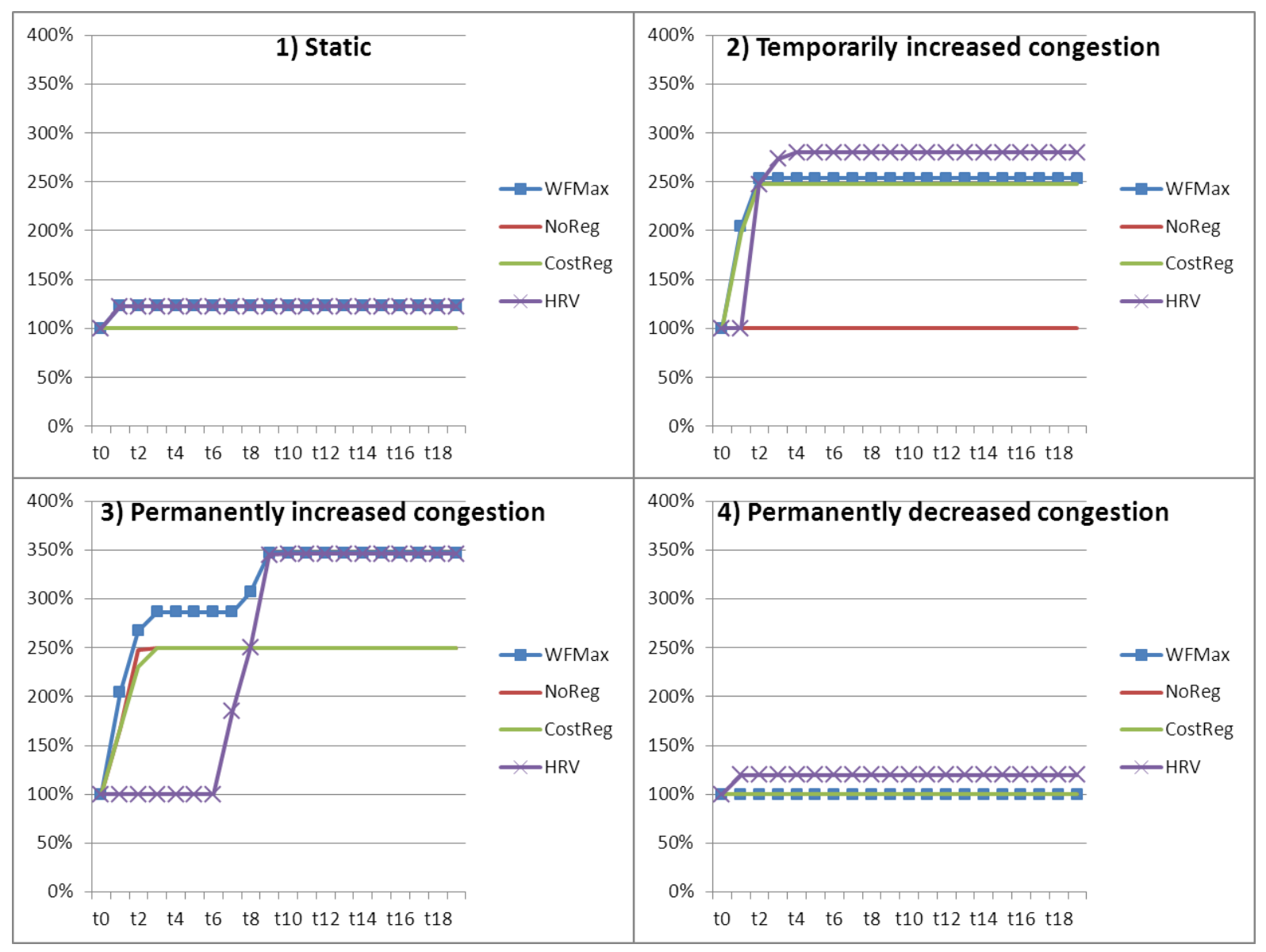

Figure 9: Line extension results (relative to initial line capacity, average Laspeyres-Paasche weights)

\subsection{Welfare Effects}

As a consequence of the expansion results discussed above for each type of weight, we find the welfare results as summarized in Table 2. In the static case, the incentive regulatory scheme with Laspeyres leads to slightly less extension-related welfare improvement compared to the welfareoptimal benchmark, even though transmission capacity converges to the optimum over time. Yet in the other cases, this is no longer true due to over-investment (cases 2 and 4) or delayed investment (case 3). The cost-regulatory case even leads to slightly better outcomes in these cases.

For Paasche weights, the incentive regulatory scheme leads in the static case to less extension-related welfare compared to the welfare-optimal benchmark, as a result of heavily diverging transmission over-investment. The same is true for the other cases, except for 3 , in which the negative effect of slight overinvestment is more than compensated by quick expansion, compared to gradual network upgrades in the Laspeyres case. ${ }^{20}$ Cost-plus regulation still noticeable leads to better welfare outcomes in cases 1, 2 and 3. So, even though Paasche weights are easy to obtain for the regulator, they seem to be relatively inappropriate for incentive regulation in the context of a changing generation mix.

\footnotetext{
${ }^{20}$ This feature of Paasche weights may be beneficial in the case of lumpy network investments.
} 
Incentive regulation under ideal weights provides the best welfare results as expected, both compared to the other weight alternatives or even to cost regulation. Combining Paasche weight with Laspeyres weights, however, provides diverse outcomes. In the static case, average Laspeyres-Paasche weights lead to welfare effects equal to the welfare-optimal results. However, they are between Laspeyres and Paasche weights for case 2 and 3, and similar to Paasche weights in case 4 .

Table 2: Welfare changes relative to the case without extension

\begin{tabular}{llrrrr}
\hline Weights & 1) Static & $\begin{array}{r}\text { 2) Temporarily } \\
\text { increased } \\
\text { congestion }\end{array}$ & $\begin{array}{r}\text { 3) Permanently } \\
\text { increased } \\
\text { congestion }\end{array}$ & $\begin{array}{r}\text { 4) Permanently } \\
\text { decreased } \\
\text { congestion }\end{array}$ \\
\hline WFMax & & $0.29 \%$ & $1.28 \%$ & $11.62 \%$ & $0.00 \%$ \\
NoReg & & $0.00 \%$ & $0.00 \%$ & $9.25 \%$ & $0.00 \%$ \\
CostReg & & $0.00 \%$ & $1.27 \%$ & $9.22 \%$ & $0.00 \%$ \\
& Laspeyres & $0.25 \%$ & $1.01 \%$ & $9.02 \%$ & $-0.17 \%$ \\
& Paasche & $-0.11 \%$ & $0.38 \%$ & $9.39 \%$ & $-0.32 \%$ \\
& Av. Lasp.-P. & $0.29 \%$ & $0.89 \%$ & $9.21 \%$ & $-0.32 \%$ \\
& Ideal & $0.29 \%$ & $1.28 \%$ & $11.62 \%$ & $0,00 \%$ \\
\hline
\end{tabular}

Thus, incentive regulation might still provide relatively adequate outcomes in terms of welfare convergence, as long as the proper types of weights are used. Ideal weights always lead to convergence to the welfare-optimum, but are not available for the regulator in complex networks. Accordingly, the regulator might actually choose the best practically available weights that can be observed from market outcomes under incentive regulation for each assumed congestion behavior:

- No exogenous change of network congestion: Average Laspeyres-Paasche weights provide the best results due to quick network expansion, but Laspeyres weights also work well.

- Temporarily-increased-congestion case: Laspeyres weights work best, average LaspeyresPaasche weights fall somewhat short.

- Permanently-increasing-congestion case: Paasche weights work best, while average Laspeyres-Paasche weights provide the second best outcome.

- Permanently-decreasing-congestion case: Incentive regulation with other than ideal weights does not lead to desirable outcomes, as the Transco is rewarded for network investments that are obsolete in later periods (stranded investments).

Regarding questions of real-world renewable integration, cases 2) and 3) appear to be most relevant. Whereas Laspeyres weights work best in case 2) and Paasche weights are preferable in case 3), average Laspeyres-Paasche weights appear to be a robust choice in both cases. That is, the regulator 
may choose average Laspeyres-Paasche weights if it is not clear if the expected exogenous increase in network extension is a permanent or a transitory one.

\section{Conclusions}

In this paper we addressed transmission investment in the context of a renewable integration process. That is, transmission capacity expansion is driven by the arousal of new centralized and zero variable cost wind generation, which compensates conventional generation capacities. We compared incentive price-cap, cost-of-service and non-regulated regulatory approaches in dynamic systems which assume the transformation towards a renewable-based system. In previous research, the complex issue of interaction between generation, transmission and demand had not yet been considered in the regulation of transmission expansion. In real world, transmission investment is not the only source of welfare change; another possible source is the shift towards renewables in the power plant fleet, which is considered exogenous here. Even in a one-period decision setting, designing a regulated tariff scheme which sets the right incentives for welfare optimal transmission expansion in a changing generation technology environment is challenging. The regulatory design issue even becomes more cumbersome in the light of several consecutive periods and dynamic exogenous factors, like incentives for increase in renewable generation capacity.

We found in this document that changes in the generation mix imply two sources on welfare change: i) the network expansion process itself and ii) the shift in generation technologies (in our stylized settings, more wind and solar as opposed to conventional base-load generation). Compared to the welfare optimal solution, this, in turn, may translate into (stranded) overinvestments in the transmission network for incentive price-cap (HRV) regulation due to excessive rents accruing to the Transco, some of them purely originating from a changing generation technology. In the same generation-mix cases, cost-of-service regulation in contrast can provide investment behaviors close to the welfare-optimal ones. This suggests that, in order to capture the full gains of incentive regulation, the regulator should aim to differentiate the generation rents from gains coming from network expansions, so as to efficiently guide the transmission expansion process and minimizing welfare losses.

Under a renewable integration process the definition of appropriate weights that lead to welfare convergence with HRV regulation arises then as a challenge for the regulator. In our stylized application, Laspeyres weights only reflect the above mentioned non-differentiated sources on welfare, and therefore over-compensate the Transco that may over- or underinvest in network expansion. The complexities in real-world renewable integration would then need that the regulator precisely differentiates the sources of welfare change in the transmission expansion process while implementing incentive regulation. In our simulations, the use of quasi-ideal weights (related to Laffont and Tirole, 1996) achieves this goal and allows for early convergence in investment and welfare values of 
incentive regulation to the welfare optimal benchmark. However, the actual implementation of ideal weights seems challenging in regulatory real-world practice.

The challenge would be finding a practically obtainable new type of weight that provides the required incentives under renewable integration. None of the evaluated weights (except for ideal ones) are able to incentivize welfare optimal network investments. Yet our results indicate that Laspeyres, Paasche or average Laspeyres-Paasche weights may be appropriate choices, depending on the permanent or transitory nature of exogenously increasing network congestion attributable, for example, to the buildup of renewable generation capacity. In particular, Laspeyres-Paasche weights could be of interest in case that the duration of the exogenous congestion shock is not known. In addition, these weights lead to earlier investments compared to Laspeyres weights, which may be beneficial if a requirement of substantial future network investment for renewable integration is anticipated. In any case, the choice of weights depends on the regulator's expectations on the exogenously driven development of congestion rents.

Our analysis thus motivates further research on weight regulation aimed to characterize optimal regulation for transmission expansion under a transformation towards a renewable-based power system. This task may be more complex in the context of meshed loop-flowed networks, since the welfare effects from transmission expansion and a changing mix in generation technologies are more difficult to isolate. Although our analysis is motivated by renewable energy integration, our findings may be interpreted in a more general context. Exogenous congestion changes may not only originate from renewable integration, as assumed here, but also from other developments in the generation mix, or from changes in power demand. 


\section{Appendix}

Table 4: Sets and indices, parameters, variables

\begin{tabular}{|c|c|c|}
\hline Symbol & Description & Unit \\
\hline \multicolumn{3}{|l|}{ Sets and indices: } \\
\hline $\mathrm{n}, \mathrm{nn} \in \mathrm{N}$ & Nodes & \\
\hline$l \in \mathrm{L}$ & Line & \\
\hline $\mathrm{s} \in \mathrm{S}$ & Generation technology & \\
\hline$t \in T$ & Regulatory time periods & years \\
\hline$\tau \in \mathrm{T}$ & Dispatch time periods & hours \\
\hline \multicolumn{3}{|l|}{ Parameters: } \\
\hline$m_{n, \tau}$ & Slope of demand function & \\
\hline$a_{n, \tau}$ & Intercept of demand function & \\
\hline $\bar{g}_{n, s}$ & Maximum hourly generation capacity & MWh \\
\hline$C_{s}$ & Variable generation costs & $€ / \mathrm{MWh}$ \\
\hline$e c_{l}$ & Line extension costs & $€ / \mathrm{MW}$ \\
\hline$\varepsilon$ & Price elasticity of demand at reference point & \\
\hline$P_{l}^{0}$ & Initial line capacity & MW \\
\hline$I_{l, n}$ & Incidence matrix & \\
\hline$X_{l}^{0}$ & Initial line reactance & $\Omega$ \\
\hline$B_{n, n n, t}$ & Network susceptance matrix of period $t$ & $1 / \Omega$ \\
\hline slack $_{n}$ & Slack node (1 for one node, 0 for all others) & \\
\hline$\delta^{s}$ & Social discount rate & \\
\hline$\delta^{p}$ & Private discount rate & \\
\hline$r$ & Return on costs (in case of cost-based regulation) & \\
\hline \multicolumn{3}{|c|}{ (2) } \\
\hline$w f$ & Overall welfare & $€$ \\
\hline$\Pi$ & Transco profit & $€$ \\
\hline$q_{n, t, \tau}$ & Hourly demand & MWh \\
\hline$g_{n, s, t, \tau}$ & Hourly generation & MWh \\
\hline$p_{n, t, \tau}$ & Hourly electricity price & $€ / \mathrm{MWh}$ \\
\hline$\Delta_{n, t, \tau}$ & Voltage angle & \\
\hline$\lambda_{1, l, t, \tau}$ & Shadow price of positive line capacity constraint & $€ / \mathrm{MWh}$ \\
\hline$\lambda_{2, l, t, \tau}$ & Shadow price of negative line capacity constraint & €/MWh \\
\hline$p_{n, t, \tau}=\lambda_{3, n, t, \tau}$ & Shadow price of market clearing constraint (electricity price) & €/MWh \\
\hline$\lambda_{4, n, s, t, \tau}$ & Shadow price of generation capacity constraint & $€ / \mathrm{MWh}$ \\
\hline$\lambda_{5, n, t, \tau}$ & Shadow price of slack constraint & $€ / \mathrm{MWh}$ \\
\hline$e x t_{l, t}$ & Line extension & MW \\
\hline$P_{t, t}$ & Line capacity of period $t$ & MW \\
\hline$X_{l, t}$ & Line reactance of period t & $\Omega$ \\
\hline fixpart $_{t}^{\text {CostReg }}$ & Fix tariff part in case of cost-based regulation & $€$ \\
\hline fixpart $_{t}^{H R V}$ & Fix tariff part in case of $H R V$ regulation & $€$ \\
\hline
\end{tabular}




\section{ISO's constrained welfare maximization problem}

$$
\begin{aligned}
& \max _{\substack{q, g, \Delta, \lambda_{1}, \lambda_{2}, p, \lambda_{4}, \lambda_{5},}} \sum_{t \in T}\left(\sum_{\tau \in \mathrm{T}} \sum_{n \in N}\left(\int_{0}^{q_{n, t, \tau}^{*}} p_{n, t, \tau}\left(q_{n, t, \tau}\right) d q_{n, t, \tau}-\sum_{s \in S} c_{s} g_{s, n, t, \tau}\right) \frac{1}{\left(1+\delta_{s}\right)^{t-1}}\right) \\
& \text { s.t. } \sum_{n} \frac{I_{l, n}}{X_{l, t}} \Delta_{n, t, \tau}-P_{l, t} \leq 0 \quad\left(\lambda_{1, l, t, \tau}\right) \quad \forall l, t, \tau \\
& -\sum_{n} \frac{I_{l, n}}{X_{l, t}} \Delta_{n, t, \tau}-P_{l, t} \leq 0 \quad\left(\lambda_{2, l, t, \tau}\right) \quad \forall l, t, \tau \\
& \sum_{s} g_{n, s, t, \tau}-\sum_{n n} B_{n, n n} \Delta_{n n, t, \tau}-q_{n, t, \tau}=0\left(p_{n, t, \tau}\right) \quad \forall n, t, \tau \\
& g_{n, s, t, \tau}-\bar{g}_{n, s} \leq 0 \quad\left(\lambda_{4, n, s, t, \tau}\right) \quad \forall n, s, t, \tau \\
& \operatorname{slack}_{n} \Delta_{n, t, \tau}=0 \quad\left(\lambda_{5, n, t, \tau}\right) \quad \forall n, t, \tau
\end{aligned}
$$

\section{References}

50Hertz, Amprion, TenneT, TransnetBW (2012): Netzentwicklungsplan Strom 2012. 2. Überarbeiteter Entwurf der Übertragungsnetzbetreiber. Berlin, Dortmund, Bayreuth, Stuttgart, 15. August 2012.

Alesina, A., S. Ardagna, G. Nicoletti, and F. Schiantarelli (2005), Regulation and Investment, Journal of the European Economic Association, 3(4), 791-825.

Armstrong, M., S. Cowan, and J. Vickers (1994), Regulatory reform: Economic analysis and British experience, MIT Press, Cambridge.

Bertoletti, P., and C. Poletti (1997), Welfare Effects of Discriminatory Two-Part Tariffs Constrained by Price Caps, Economics Letters, 56, 292-298.

Bushnell, J.B. and S.E. Stoft (1997), Improving private incentives for electric grid investment, Resource and Energy Economics, 19, 85-108.

Contreras, J., G. Gross, J.M. Arroyo and J.I. Muñoz (2009), An incentive-based mechanism for transmission asset investment, Decision Support Systems, 47, 22-31.

Gabriel, S.A., A.J. Conejo, J.D. Fukker, B.F. Hobbs, and C. Ruiz (2013), Complementary Models in Energy Markets, Springer.

Hobbs, B.F., C.B. Metzler and J.S. Pang (2000), Strategic gaming analysis for electric power systems: an MPEC approach, IEEE Transactions on Power Systems, 15(2), 638-645. 
Hogan, W., J. Rosellón, and I. Vogelsang (2010), Toward a Combined Merchant-Regulatory Mechanism for Electricity Transmission Expansion, Journal of Regulatory Economics, 38(2), 113143.

Joskow, P. and J. Tirole (2002), Transmission Investment: Alternative Institutional Frameworks, IDEI (Industrial Economic Institute), Toulouse, France, (http://idei.fr/doc/conf/wme/tirole.pdf).

Kristiansen, T. and J. Rosellón (2006), A Merchant Mechanism for Electricity Transmission Expansion, Journal of Regulatory Economics, 29(2), 167-193.

Léautier, T.-O. (2000), Regulation of an Electric Power Transmission Company, The Energy Journal, 21, 61-92.

Laffont, J.J., and J. Tirole (1996), Creating Competition through Interconnections: Theory and Practice. Journal of Regulatory Economics, 10, 227 -256.

Leuthold, F., H. Weigt, and C.v. Hirschhausen (2012), A Large-Scale Spatial Optimization Model of the European Electricity Market, Networks and Spatial Economics, 12(1), 75-107.

Loeb, M., and W.A. Magat (1979), A Decentralized Method of Utility Regulation, Journal of Law and Economics, 22, 399-404.

Newbery, D. (2005), Electricity liberalisation in Britain: The quest for a satisfactory wholesale market design, The Energy Journal, European Energy Liberalisation Special Issue, 26, 43-70.

Pollitt, M.G., S. Davies, C.W. Price, J. Haucap and M. Mulder (2007), Vertical Unbundling in the EU Electricity Sector, Intereconomics, Forum, 42(6), 292-310.

Rosellón, J. and H. Weigt (2011), A Dynamic Incentive Mechanism for Transmission Expansion in Electricity Networks - Theory, Modeling and Application, The Energy Journal, 32(1), 119-148.

Rosellón, J., I. Vogelsang, and H. Weigt (2012), Long-run Cost Functions for Electricity Transmission, The Energy Journal, 33(1), 131-160.

Rosellón, J., Z. Myslíková, and E. Zenón (2011), Incentives for Transmission Investment in the PJM Electricity Market: FTRs or Regulation (or both?), Utilities Policy, 19 (1), 3-13.

Rubio, F.J. and I.J. Pérez-Arriaga (2000), Marginal Pricing of Transmission Services: A Comparative Analysis of Network Cost Allocation Methods, IEEE Transactions on Power Systems, 15(1), 448454.

Ruiz, E. and J. Rosellón (2012), Transmission Investment in the Peruvian Electricity Market: Theory and Applications, Energy Policy, 47, 238-245.

Sauma, E.E. And S. Oren (2007), Economic criteria for planning transmission investment in restructured electricity markets, IEEE Transactions on Power Systems, 22(4). 
Schill, W.P., J. Rosellón and J. Egerer (2011), Regulated Expansion of Electricity Transmission Networks: the Effects of Fluctuating Demand and Wind Generation, DIW Berlin Discussion Papers, 1109.

Schweppe, F.C., M.C. Caramanis, R.D. Tabors, and R.E. Bohn (1988), Spot Pricing of Electricity. Kluwer Academic Publishers, Boston/Dordrecht/London.

Sibley, D. (1989), Asymmetric Information, Incentives and Price-Cap Regulation, RAND Journal of Economics, 20, 392-404.

Tanaka, M. (2007), Extended Price Cap Mechanism for Efficient Transmission Expansion under Nodal Pricing, Network and Spatial Economics, 7, 257-275.

Van der Weijde, A.H. and B.F. Hobbs (2012), The economics of planning electricity transmission to accommodate renewables: Using two-stage optimisation to evaluate flexibility and the cost of disregarding uncertainty, Energy Economics, 34(6), 2089-2101.

Vogelsang, I. (2001), Price Regulation for Independent Transmission Companies, Journal of Regulatory Economics, 20(2), 141-165.

Vogelsang, I. (1989), Two-Part Tariffs as Regulatory Constraints, Journal of Public Economics, 39, 45-66.

Vogelsang, I. (1988), A Little Paradox in the Design of Regulatory Mechanisms, International Economic Review, 29(3), 467-476. 